Vol. 6, No. 1 Januari - Juni 2017

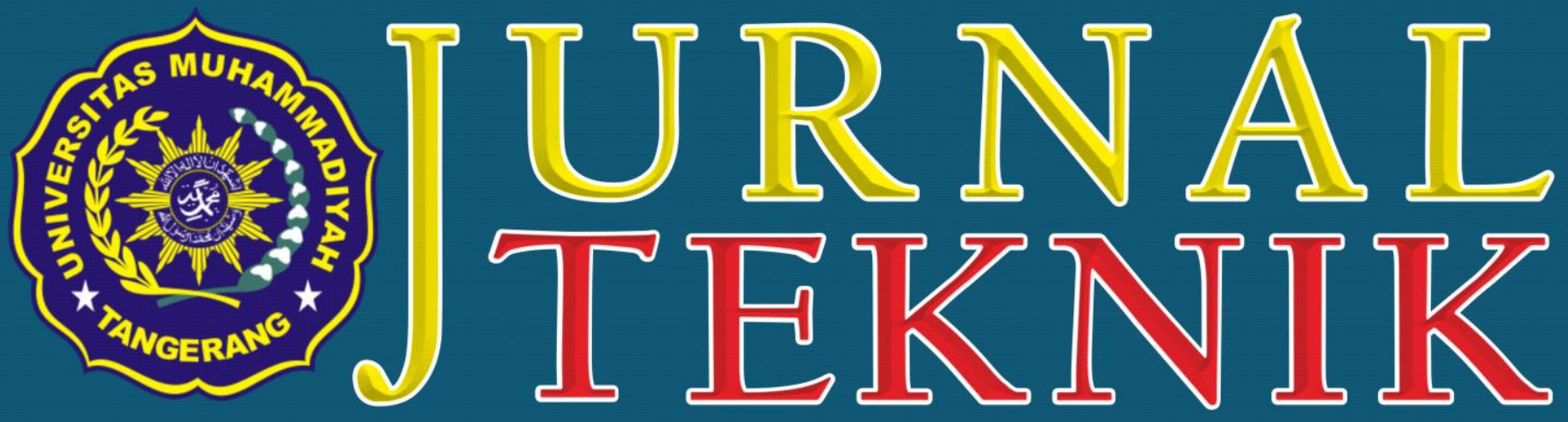

Alamat Redaksi: Jl. Perintis Kemerdekaan I No. 33, Cikokol Tangerang - TIp. (021) 51374916

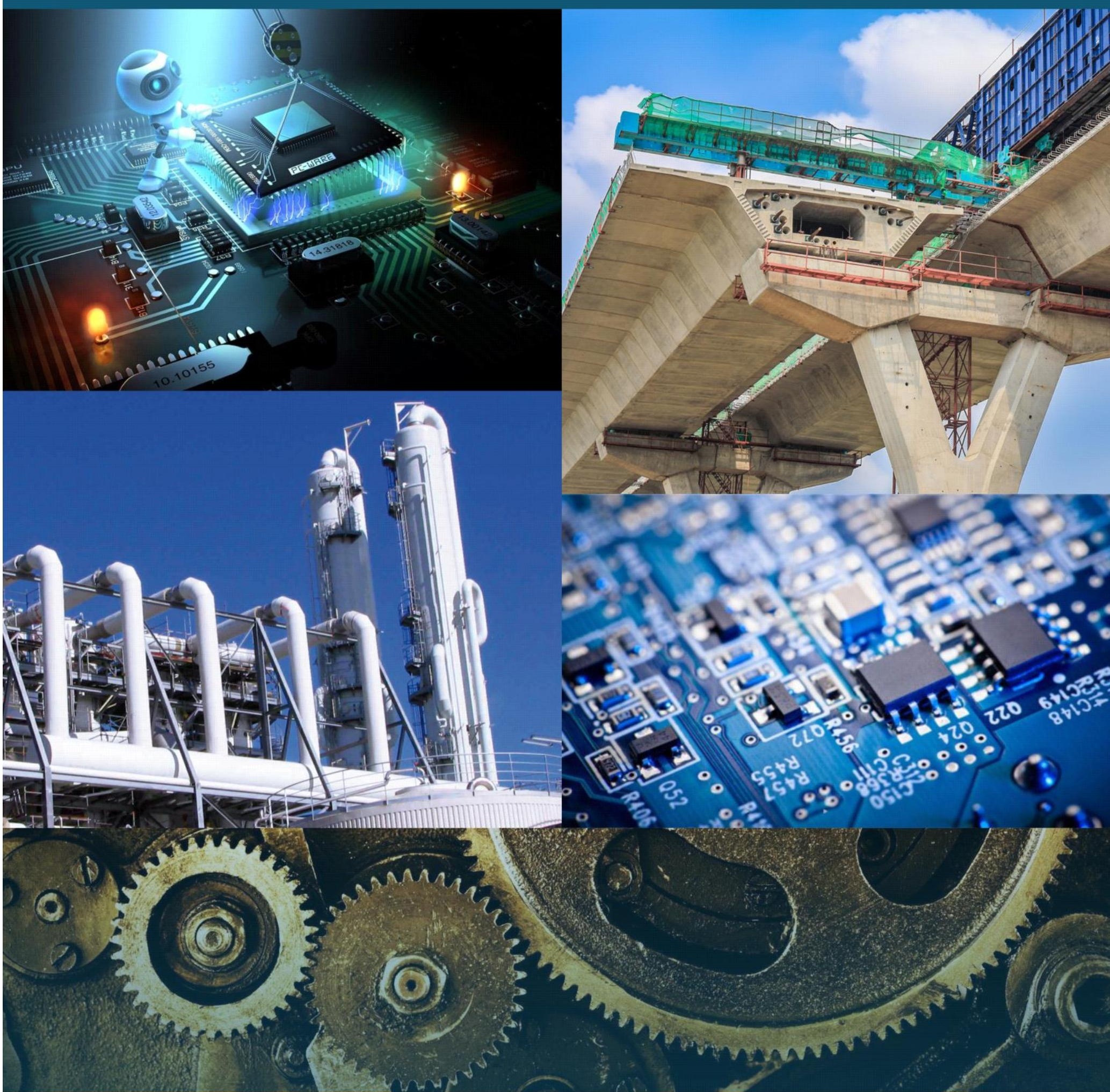




\section{J U R N A L TEKN I K}

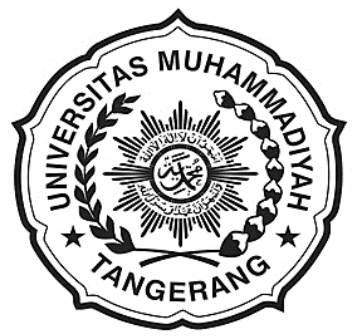

\section{UNIVERSITAS MUHAMMADIYAH TANGERANG}

Pelindung:

Dr. H. Achmad Badawi, S.Pd., SE., MM. (Rektor Universitas Muhammadiyah Tangerang)

Penanggung Jawab:

Ir. Saiful Haq, ST., M.Si.

(Dekan Fakultas Teknik)

Pembina Redaksi:

Rohmat Taufik, ST., M.Kom.

Drs. H. Syamsul Bahri, MSi.

Pimpinan Redaksi:

Ir. Sumardi Sadi, S.Pd., ST., MT.

Redaktur Pelaksana:

Yafid Efendi, ST, MT.

Editor Jurnal Teknik UMT:

Ir. Sumardi Sadi, S.Pd., ST., MT.

Dewan Redaksi:

Ir. Ali Rosyidin, ST., MM., MT.

Tri Widodo, ST.,MT.

Tina Herawati, ST., MT

Almufid, ST., MT.

Siti Abadiah, ST., MT.

M. Jonni, SKom., MKom.

Syepry Maulana Husain, S.Kom., M.Kom.

Ir. H. Bayu Purnomo, ST., MT

Kasubag:

Ferry Hermawan, MM.

Keuangan:

Elya Kumalasari, S.Ikom.

Setting \& Lay Out:

Muhlis, S.E

Saiful Alam, SE.

Mitra Bestari:

Prof. Dr. Aris Gumilar

Ir. Doddy Hermiyono, DEA

Dr. Ir. Budiyanto, MT.

Dr. Alimuddin, ST., MM., MT

J U R N A L T E K N I K

Diterbitkan Oleh:

Fakultas Teknik Universitas Muhammadiyah Tangerang

Alamat Redaksi:

Jl. Perintis Kemerdekaan I No. 33, Cikokol Tangerang Tlp. (021) 51374916

\begin{tabular}{|c|c|c|c|c|c|}
\hline \multirow{2}{*}{$\begin{array}{c}\text { Jurnal } \\
\text { Teknik }\end{array}$} & 6 & 1 & $1-97$ & $\begin{array}{c}\text { Jan'-Juni } \\
2017\end{array}$ & ISSN \\
\cline { 2 - 6 } & $2302-8734$ \\
\hline
\end{tabular}

\section{DAFTAR ISI}

1. PROSES PEMBUATAN ALAT PEMBUKA KALENG CAT DENGAN METODE CETAK PASIR (SAND CASTING) - 1-11 Ali Rosyidin

2. ANALISA DAN PERANCANGAN SISTEM KENDALI PLC XBC MINI BAS - 12-18 Alim Hardiansyah \& Bambang Suardi Waluyo

3. PENGATUR KESTABILAN SUHU PADA EGG INCUBATOR BERBASIS ARDUINO - 19-22

Abel Putra Hidayah \& Sumardi Sadi

4. METODE PEMBUATAN PONDASI BORE PILE DENGAN KINGPOST DAN METODE PONDASI DINDING PENAHAN TANAH DIAFRAGMA WALL - 23-29

Almufid

5. RANCANG BANGUN SIMULASI PENGENDALI LAMPU LALU LINTAS PADA PERSIMPANGAN DENGAN LIMA JALUR - 30-39

Rahma Farah Ningrum, Puji Catur Siswipraptini, \& Rosida N. Aziza

6. PERANCANGAN PROGRAM APLIKASI PENGENALAN WAJAH DENGAN MENERAPKAN METODE PRINCIPAL COMPONENT ANALYSIS DAN JARINGAN SYARAF TIRUAN - 40-49

M. Lutfi Aksani

7. KAJIAN PENERAPAN SI / TI DALAM MENINGKATKAN KUALITAS PEMBELAJARAN PADA TRAINING CENTER DENGAN MENGGUNAKAN METODOLOGI DeLone And McLean: STUDI KASUS PADA BINUS CENTER JAKARTA - 50-62 Nyoman Ayu Gita Gayatri \& GG Faniru Pakuning Desak

8. RANCANG BANGUN APLIKASI PEMBELAJARAN MATEMATIKA SD KELAS 6 BERBASIS ANDROID PADA SDN CIMONE 1 TANGERANG - 63-69

Winda Anggraeni \& Sri Mulyati

9. RANCANG BANGUN MESIN PERAJANG SINGKONG INDUSTRI RUMAHAN BERDAYA RENDAH - 70-76

Yafid Effendi \& Agus Danang Setiawan

10. RANCANG BANGUN TONGKAT ULTRASONIK UNTUK PENYANDANG TUNA NETRA BERBASIS ARDUINO UNO - 77-82

Bayu Purnomo \& Basuki Isnanto

11. ENTERPRISE RISK MANAGEMENT PADA CLOUD COMPUTING - 83-87

Samudera Dipa Legawa

12. ANALISIS NETWORK PLANNING DENGAN CRITICAL PATH METHOD (CPM) PADA PROYEK UNINTERATUBLE POWER SUPPLY (UPS) 80KVA PADA PT. HARMONI MITRA SUKSES (STUDI KASUS: RSAB HARAPAN KITA, JAKARTA) - 88-97

Hermanto, Novy Fauziah, \& Elfitria Wiratmani 


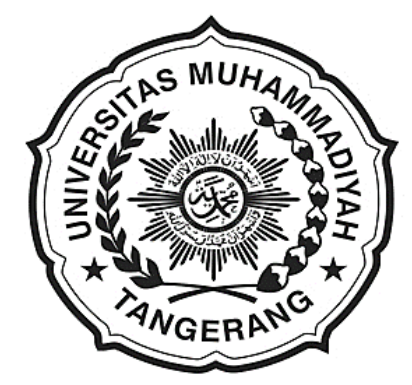

\section{Sambutan Dekan \\ Fakultas Teknik \\ Universitas Muhammadiyah Tangerang}

Puji Syukur kehadirat Allah Swt. karena berkat karunia dan ijin-Nyalah Tim penyusun Jurnal Teknik Fakultas Teknik Universitas Muhammadiyah Tangerang dapat menyelesaikan tugasnya tepat sesuai dengan waktu ditetapkan.

Saya menyambut baik diterbitkannya Jurnal Teknik Vol. 6 No. 1, Januari-Juni 2017, terbitnya jurnal ini, merupakan respon atas terbitnya Peraturan Menteri Pendidikan Nasional No. 17 Tahun 2010 tentang Pencegahan dan Penanggulangan Plagiat di Perguruan Tinggi; Surat Dirjen Dikti Nomor 2050/E/T/2011 tentang kebijakan unggah karya ilmiah dan jurnal; Surat Edaran Dirjen Dikti Nomor 152/E/T/2012 tertanggal 27 Januari 2012 perihal publikasi karya ilmiah yang antara lain menyebutkan untuk lulusan program sarjana terhitung mulai kelulusan setelah 2012 harus menghasilkan makalah yang terbit pada jurnal ilmiah.

Terbitnya Jurnal ini juga diharapkan dapat mendukung komitmen dalam menunjang peningkatan kemampuan para dosen dan mahasiswa dalam menyusun karya ilmiah yang dilandasi oleh kejujuran dan etika akademik. Perhatian sangat tinggi yang telah diberikan rektor Universitas Muhammadiyah Tangerang khususnya mengenai plagiarism dan cara menghindarinya, diharapkan mampu memacu semangat dan motivasi para pengelola jurnal, para dosen dan mahasiswa dalam menyusun karya ilmiah yang semakin berkualitas.

Saya mengucapkan banyak terimakasih kepada para penulis, para pembahas yang memungkinkan jurnal ini dapat diterbitkan, dengan harapan dapat dimanfaatkan seoptimal mungkin dalam peningkatan kualitas karya ilmiah.

Dekan Fakultas Teknik

Universitas Muhammadiyah Tangerang,

\section{Ir. Saiful Haq, M.Si.}




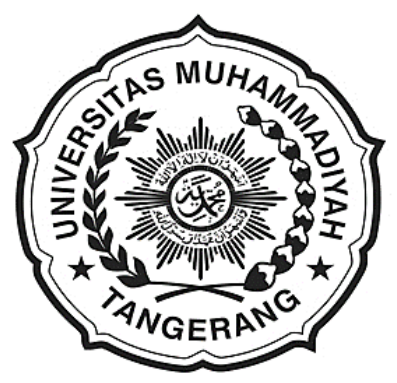

\section{Pengantar Redaksi}

Jurnal Teknik

Universitas Muhammadiyah Tangerang

Puji dan Syukur Alhamdulillah kami panjatkan kehadapan Allah Swt. atas karunia dan lindungan-Nya sehingga Jurnal Teknik Vol. 6 No. 1 edisi Januari-Juni 2017 dapat diterbitkan.

Menghasilkan karya ilmiah merupakan sebuah tuntutan perguruan tinggi di seluruh dunia. Tri Dharma Perguruan Tinggi yaitu darma pendidikan, darma penelitian, dan darma pengabdian kepada masyarakat mendorong lahirnya dinamika intelektual diantaranya menghasilkan karyakarya ilmiah. Penerbitan Jurnal Teknik ini dimaksudkan sebagai media dokumentasi dan informasi ilmiah yang sekiranya dapat membantu para dosen, staf dan mahasiswa dalam menginformasikan atau mempublikasikan hasil penelitian, opini, tulisan dan kajian ilmiah lainnya kepada berbagai komunitas ilmiah.

Buku Jurnal yang sedang Anda pegang ini menerbitkan 12 artikel yang mencakup bidang teknik sebagaimana yang tertulis dalam daftar isi dan terdokumentasi nama dan judul-judul artikel dengan jumlah halaman 1-97 halaman.

Jurnal Teknik ini tentu masih banyak kekurangan dan masih jauh dari harapan, namun demikian tim redaksi berusaha untuk ke depannya menjadi lebih baik dengan dukungan kontribusi dari semua pihak. Harapan Jurnal Teknik akan berkembang menjadi media komunikasi intelektual yang berkualitas, aktual dan faktual sesuai dengan dinamika di lingkungan Universitas Muhammadiyah Tangerang.

Tak lupa pada kesempatan ini kami mengundang pembaca untuk mengirimkan naskah ringkasan penelitiannya ke redaksi kami. Kami sangat berterimakasih kepada semua pihak yang telah membantu penerbitan Jurnal Teknik ini semoga buku yang sedang Anda baca ini dapat bermanfaat.

Pimpinan Redaksi Jurnal Teknik

Universitas Muhammadiyah Tangerang,

Ir. Sumardi Sadi, S.Pd., ST., MT. 


\title{
RANCANG BANGUN TONGKAT ULTRASONIK UNTUK PENYANDANG TUNA NETRA BERBASIS ARDUINO UNO
}

\author{
Bayu Purnomo ${ }^{1)}$, Basuki Isnanto ${ }^{2)}$ \\ ${ }^{1,2)}$ Program Studi Teknik Elektro \\ Universitas Muhammadiyah Tangerang \\ Jl. Perintis Kemerdekaan I/33, Cikokol - Tangerang-Banten
}

\begin{abstract}
ABSTRAK
Tongkat ultrasonik ini dirancang dengan tujuan memberikan sedikit keringanan bagi para penyandang tuna netra dalam melakukan kegiatan sehari-hari terutama dalam hal berjalan. Perancangan tongkat elektronik ini juga didasari oleh rasa empati penulis terhadap sesama makhluk ciptaan Tuhan Yang Maha Esa untuk dapat saling membantu satu sama lain. Adapun fungsi dari tongkat ini adalah mendeteksi adanya rintangan yang akan dihadapi para tuna netra selama melakukan kegiatan berjalan didalam maupun diluar ruangan. Dengan memanfaatkan mikrokontroller jenis Arduino Uno sebagai rangkaian pengontrol, sensor distance ultrasonic jenis $P I N G$ dari Parallax dan sensor infra merah jenis IR Sharp GP2YOA21 serta memberikan indikator berupa motor DC sebagai penghasil getaran dan buzzer sebagai indikator bunyi sehingga dapat dirasakan dengan baik oleh penggunanya.
\end{abstract}

Kata Kunci: Tongkat, Tuna Netra, Arduino Uno, sensor ultrasonik, sensor Optic IR Sharp GP2YOA21.

\section{LATAR BELAKANG}

Indera penglihatan adalah salah satu sumber informasi yang vital bagi manusia dan merupakan salah satu anugerah terindah dari Tuhan Yang Maha Esa. Tidak berlebihan apabila dibenarkan bahwa sebagian besar informasi yang diperoleh oleh manusia berasal dari indera penglihatan, sedangkan selebihnya berasal dari panca indera yang lain. Dengan mata, manusia bisa merekam dan mengetahui objek yang dilihatnya. Oleh karenanya indera yang satu ini sangat bagi kelancaran aktivitas manusia sehari-hari. Sebagai akibatnya, apabila seseorang mengalami gangguan pada indera penglihatannya, maka kemampuam aktifitas akan sangat terbatas, karena informasi yang diperoleh akan jauh berkurang dibandingkan mereka yang berpenglihatan normal.

Tidak semua manusia dianugerahi oleh Tuhan Yang Maha Esa dengan mata yang normal. Diantara kita ada yang mengalami gangguan penglihatan sejak lahir atau karena sesuatu hal yang akhirnya menyebabkan indera penglihatannya terganggu dan tidak lagi bekerja dengan normal. Dan orang yang mengalami ganngguan penglihatan disebut tuna netra.

Tuna netra menurut Kamus Besar Bahasa Indonesia adalah tidak dapat melihat (KBBI, 1989: p.971) dan menurut literatur berbahasa Inggris yaitu visually handicapped atau visually impaired. Secara etimologis, kata tuna berarti luka, rusak, kurang atau tiada memiliki, netra berarti mata atau penglihatan. Jadi tuna netra berarti kondisi luka atau rusaknya mata, sehingga mengakibatkan kurang atau tidak memiliki kemampuan persepsi penglihatan.

Dari pengertian tersebut dapat dirumuskan bahwa istilah tuna netra mengandung arti rusaknya penglihatan. Rumusan ini pada dasarnya belum lengkap dan jelas karena belum tergambarkan apakah keadaan mata yang tidak dapat melihat sama sekali atau mata rusak tetapi masih dapat melihat, atau juga berpenglihatan sebelah.

Tuna netra memang mempunyai masa- 
lah dalam segi melihat. Masalah yang kerap dihadapi para tuna netra misalnya sulit mendeteksi halangan yang ada di depan mereka, adanya lubang, batu atau permukaan tanah yang tidak rata juga salah satu dari banyak kendala yang dihadapi oleh para tuna netra dalam beraktivitas. Akan tetapi, sebagian besar tuna netra masih bisa beraktivitas walaupun ruang lingkup kerja mereka masih sangat terbatas. Oleh karena itu mereka membutuhkan sebuah alat yang bisa meringankan dan membantu mereka dalam beraktivitas, salah satu alat bantu tersebut adalah tongkat.

Tongkat merupakan alat bantu yang paling sering digunakan para tuna netra. Dengan adanya tongkat setidaknya sedikit memberikan kemudahan bagi para tuna netra. Diantara mereka ada yang menggunakan tongkat yang terbuat dari kayu, melainkan ada juga yang membeli tongkat dengan rekomendasi dari dokter yang sudah banyak dijual. Bukan hanya tongkat yang menjadi alat bantu untuk para tuna netra, seiring dengan perkembangan zaman maka muncul banyak alat bantu yang lebih canggih diantaranya sensor wand for the blind, privateye 3.0, GPS, ultracane dan kacamata bionic

Walaupun mulai bermunculan alat bantu navigasi bagi tuna netra, tongkat masih menjadi pilihan utama karena harganya yang relatif murah. Namun tongkat masih memiliki kekurangan yaitu hanya dapat digunakan untuk meraba benda atau halangan dengan jangkauan yang terbatas. Hal ini membuat penyandang tuna netra dituntut untuk selalu waspada serta merasa khawatir jika sedang berjalan sendirian.

Atas dasar hal tersebut diatas dan juga dengan kemajuan teknologi khususnya di bidang teknik elektro maka penulis membuat tulisan dengan judul "Rancang Bangun Tongkat Ultrasonik Untuk Penyandang Tuna Netra Berbasis Arduino Uno". Tongkat ultrasonik ini dirancang dengan tujuan memberikan sedikit keringanan bagi para penyandang tuna netra dalam melakukan kegiatan sehari-hari terutama dalam hal berjalan. Perancangan tongkat elektronik ini juga didasari oleh rasa empati penulis terhadap sesama makhluk ciptaan Tuhan Yang Maha Esa untuk dapat saling mem- bantu satu sama lain. Adapun fungsi dari tongkat ini adalah mendeteksi adanya rintangan yang akan dihadapi para tuna netra selama melakukan kegiatan berjalan didalam maupun diluar ruangan. Dengan memanfaatkan mikrokontroller jenis Arduino Uno sebagai rangkaian pengontrol, sensor distance ultrasonic jenis PING dari Parallax dan sensor infra merah jenis GP2Y0A21 serta memberikan indikator berupa motor $D C$ sebagai penghasil getaran dan buzzer sebagai indikator bunyi sehingga dapat dirasakan dengan baik oleh penggunanya.

\section{RUMUSAN MASALAH}

1. Bagaimana membuat desain rangkaian elektronik dari rancang bangun tongkat ultrasonik pendeteksi halangan dan jalan berlubang bagi tuna netra?

2. Bagaimana program Arduino Uno dari rancang bangun tongkat ultrasonik pendeteksi halangan dan jalan berlubang bagi tuna netra?

3. Bagaimana informasi yang disampaikan oleh tongkat elektronik melalui sensor utrasonik $P I N G$ dan sensor IR GP2YOA21 sehingga bisa diterima oleh tuna netra dengan baik ?

\section{TUJUAN DAN MANFAAT PENULISAN}

\subsection{Tujuan dari penulisan}

1. Merancang sebuah prototype tongkat ultrasonik sebagai alat bantu untuk penyandang tuna netra dengan menggunakan teknologi Arduino Uno yang dapat memberikan sedikit keringanan bagi para penyandang tuna netra dalam melakukan kegiatan sehari-hari terutama dalam hal berjalan;

2. Menerapkan perkembangan teknologi bidang elektro dalam hal ini pemanfaatan mikrokontroler jenis Arduino Uno di kehidupan sehari-hari;

3. Membentuk sikap profesional sebagai lulusan sarjana teknik elektro di dunia kerja tanpa melupakan kepedulian terhadap sesama makhluk ciptaan Tuhan Yang Maha Esa; dan

4. Untuk memenuhi tuntutan kurikulum jenjang strata satu program studi teknik elektro Universitas Muhammadiyah Tangerang. 


\subsection{Manfaat penulisan}

Manfaat yang diharapkan dari perancangan tongkat ultrasonic untuk penyandang tuna netra ini adalah sebagai awal dari pengembangan tongkat tuna netra yang menggunakan teknologi penginderaan berupa sensor agar lebih efisien bagi penggunanya.

\section{METODE PENELITIAN}

Beberapa teknik berikut ditempuh dalam penelitian ini, yaitu:

1. Perancangan Alat

Perancangan meliputi perangkat keras (Hardware) serta perancangan perangkat lunak (Software).

2. Pengujian Alat

Pengujian dilakukan sebagai tolak ukur akan keberhasilan dari alat yang dibuat agar dapat berfungsi sebagaimana mestinya.

\section{TUNA NETRA DALAM \\ PANDANGAN ISLAM}

Agama Islam adalah agama yang sempurna, sempurna dalam arti tidak memerlukan penambahan, pengurangan atau perubahan. Sempurna ketinggian dan kemuliaan yang memiliki kebenaran mutlak dan sempurna dalam arti keumuman bukan hanya untuk suatu kaum atau pada satu saat tertentu. Agama Islam adalah merupakan rahmat bagi seluruh alam, memberikan jaminan kepada pemeluknya memperoleh keselamatan dan kebahagiaan di dunia dan di akhirat. Salah satu rahmat Islam adalah bahwa Islam tidak membeda-kan ummat manusia untuk menjadi manusia termulia di hadapan Allah. Firman Allah,

"Sesungguhnya orang yang paling mulia di antara kamu di sisi Allah ialah orang yang paling bertakwa di antara kamu." (QS. AlHujurat: 13)

Kesempatan untuk menjadi manusia termulia sebagai orang yang bertaqwa diberikan kepada semua manusia, kaya-miskin, pemimpin-rakyat, yang dianggap cacat atau yang tidak cacat. Agama Islam tidak bersikap diskriminatif terhadap umatnya. Orang buta, orang pincang, atau yang lainnya keberadaannya diakui di dalam Islam. Mereka bukan saja diakui eksistensinya, namun ditegaskan bahwa orang buta itu memiliki potensi sebagaimana orang yang ti- dak buta (awas), potensi menerima ajaran Agama Tauhid untuk beriman, beribadah dan bertaubat serta potensi untuk berdzikir atau berfikir yang hal ini bermanfaat baginya. Firman Allah,

"Tahukah kamu barangkali ia ingin membersihkan diri (dari dosa) atau dia (ingin) mendapatkan pengajaran, lalu pengajaran itu memberi manfaat baginya?" (QS. 'Abasa: 3-4).

Demikianlah sebagian kesempurnaan Islam, menempatkan orang yang dianggap sebagai penyandang cacat mempunyai kedudukan yang sama di hadapan Allah. Sebagai konsekuensinya maka orang buta, orang pincang, atau lainnya mempunyai kewajiban dan hak yang sama pula. Mereka itu berkewajiban untuk menuntut ilmu, agar dapat menjalankan perintah dan meninggalkan larangan. Dengan landasan ilmu dan iman yang dimilikinya. Insya Allah mereka akan memperoleh derajat yang tinggi baik di dunia maupun di akhirat.

\section{Arduino Uno}

Arduino UNO adalah sebuah board mi-crocontroler yang didasarkan pada ATmega328. Arduino Uno mempunyai 14 pin digital input/output (6 diantaranya dapat digunakan sebagai output PWM), 6 input analog, sebuah osilator crystal $16 \mathrm{MHz}$, sebuah koneksi USB, sebuah power jack, sebuah ICSP header, dan sebuat tombol reset. Arduino Uno memuat semua yang dibutuhkan untuk menunjang mikrokontroler, mudah menghubungkannya ke sebuah komputer dengan sebuah kabel $U S B$ atau mendistribusikannya dengan sebuah adaptor $A C$ ke $D C$ atau menggunakan baterai untuk memulainya.

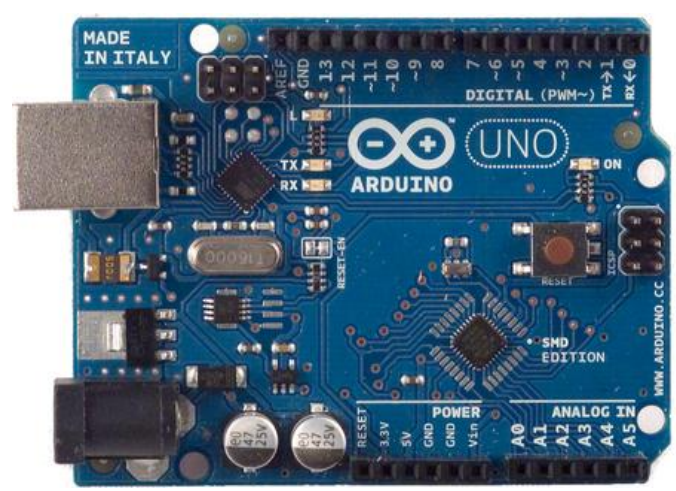

Gambar 1. Arduino Uno

(Sumber: www.peacepuyallup.org) 


\section{PERANCANGAN SISTEM KERJA SECARA UMUM}

Pembahasan pada perancangan perangkat keras dari perancangan tongkat ultrasonik untuk tuna netra ini: pertama, perancangan alur kerja rangkaian yaitu tentang rancangan awal cara kerja alat secara bertahap; kedua, pembahasan tentang rangkaian alat yang; dan ketiga, perancangan maket alat yang membahas tentang rancangan bentuk jadi alat.

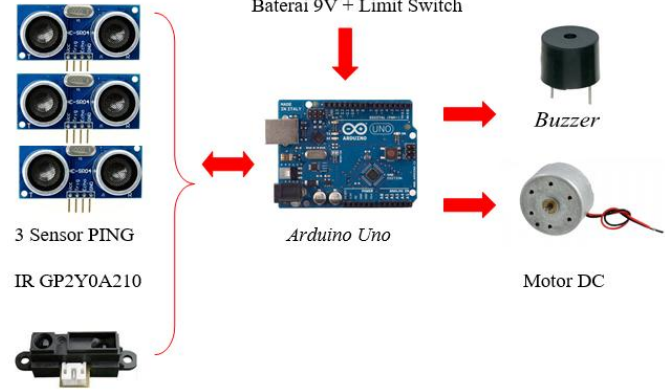

Gambar 2. Perancangan sitem kerja secara umum (Sumber: www.google.com).

Desain sistem di atas merupakan gambaran umum mengenai prinsip kerja dari tongkat ultrasonik untuk penyandang tuna netra. Dimana Arduino Uno sebagai pusat pengendali yang memberikan input ke sensor ultrasonik PING yang memancarkan sinyalnya oleh Transmitter kemudian sinyal yang kembali akan diterima oleh receiver yang terdapat pada Sensor PING. Sensor PING dalam sistem ini berfungsi sebagai pendeteksi halangan atau benda yang ada di depan nantinya. Setelah sinyal diterima dari sensor, maka Arduino Uno sebagai controller akan memberikan input ke driver motor dalam hal ini adalah transistor BD139, yang akan mengontrol indikator berupa menggunakan buzzer dan motor DC dengan sistem Pulse Width Modulation $(P W M)$.

\section{ANALISIS DAN PEMBAHASAN}

Tabel 1 Pengujian Sensor Ultrasonik

\begin{tabular}{|c|c|c|}
\hline \multirow[t]{2}{*}{ NO. } & JARAK SEBENARNYA & $\begin{array}{l}\text { HASIL PENGUKURAN } \\
\text { SENSOR }\end{array}$ \\
\hline & (cm) & $(\mathrm{cm})$ \\
\hline 1 & 3 & 3 \\
\hline 2 & 10 & 10 \\
\hline 3 & 20 & 20 \\
\hline 4 & 30 & 29 \\
\hline 5 & 40 & 40 \\
\hline 6 & 50 & 49 \\
\hline 7 & 60 & $\begin{array}{l}59 \\
\end{array}$ \\
\hline 8 & 70 & 70 \\
\hline 9 & 80 & 80 \\
\hline 10 & 90 & 90 \\
\hline 11 & 100 & 98 \\
\hline 12 & 110 & 111 \\
\hline 13 & 120 & 119 \\
\hline 14 & 130 & 128 \\
\hline 15 & 140 & 140 \\
\hline 16 & 150 & 150 \\
\hline 17 & 160 & 160 \\
\hline \begin{tabular}{|l|}
18 \\
\end{tabular} & 170 & 169 \\
\hline 19 & 180 & 179 \\
\hline 20 & 190 & 189 \\
\hline 21 & 200 & 201 \\
\hline 22 & 210 & 210 \\
\hline 23 & 220 & 220 \\
\hline 24 & 230 & 230 \\
\hline 25 & 240 & 240 \\
\hline 26 & 250 & 251 \\
\hline 27 & 260 & 261 \\
\hline 28 & 270 & 269 \\
\hline 29 & 280 & 278 \\
\hline 30 & 290 & 289 \\
\hline 31 & 300 & 300 \\
\hline
\end{tabular}

Dari tabel diatas terlihat pengukuran sensor PING terhadap jarak sebenarnya masih terdapat beberapa kesalahan. Hal ini disebabkan karena masih adanya noise pada sensor itu sendiri dan pengukuran yang kurang tepat. Maka persentase kesalahan pengukuran sensor ultrasonik PING dapat dilihat pada grafik perbandingan antara pengukuran dengan mistar (jarak sebenarnya) dan hasil pengukuran sensor.

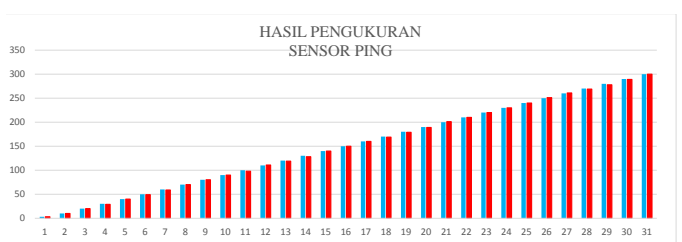

Grafik 1 Perbandingan Jarak Sebenarnya Dengan Jarak Pada Sensor PING 
Tabel 2. Pengujian Sensor Ultrasonik Berdasarkan Jenis Bahan

\begin{tabular}{|c|c|c|c|c|}
\hline \multirow{2}{*}{ NO. } & \multirow{2}{*}{ JENIS BENDA } & $\begin{array}{c}\text { JARAK } \\
\text { SEBENARNY }\end{array}$ & $\begin{array}{c}\text { HASIL } \\
\text { PENGUKURAN } \\
\text { SENSOR }\end{array}$ & \multirow{2}{*}{ KONDISI } \\
\cline { 3 - 4 } & & $(\mathrm{cm})$ & $(\mathrm{cm})$ & \\
\hline 1 & Besi & 38 & 38 & Terdeteksi \\
\hline 2 & Plastik & 38 & 38 & Terdeteksi \\
\hline 3 & Kayu & 38 & 38 & Terdeteksi \\
\hline 4 & Kertas & 38 & 37 & Terdeteksi \\
\hline 5 & Kain & 38 & 35 & Terdeteksi \\
\hline 6 & Tubuh Manusia & 38 & 37 & Terdeteksi \\
\hline 7 & Kaca & 38 & 38 & Terdeteksi \\
\hline
\end{tabular}

Dari tabel diatas dapat kita simpulkan bahwa sensor ultrasonik mempunyai hasil pengukuran yang berbeda beda sesuai dengan objek yang dideteksinya. Adanya kesalahan pengukuran oleh sensor misalnya pada kerta, kain dan tubuh manusia, menandakan bahwa variabel yang menjadi adanya perbedaan jarak pengukuran dari ketujuh objek diatas adalah waktu. Sebagaimana prinsip kerja dari sensor ultrasonik sendiri yang memancarkan gelombang dengan kecepatan $344 \mathrm{~m} / \mathrm{s}$ dan menerimanya kembali maka terjadinya variasi waktu itu berasal dari faktor bentuk permukaan dari masingmasing benda. Kain menjadi benda yang mempunyai paling banyak waktu untuk dideteksi oleh sensor, ini berarti benda- benda yang mempunyai rongga atau pori-pari dapat mempengaruhi waktu yang diperlukan sensor dalam mendeteksi suatu benda. Adapun keluaran indikator dari sensor PING ini adalah berupa buzzer yang akan berbunyi ketika kondisi yang akan berbunyi sesuai dengan program dan jarak yang sudag diatur pada Arduino Uno.

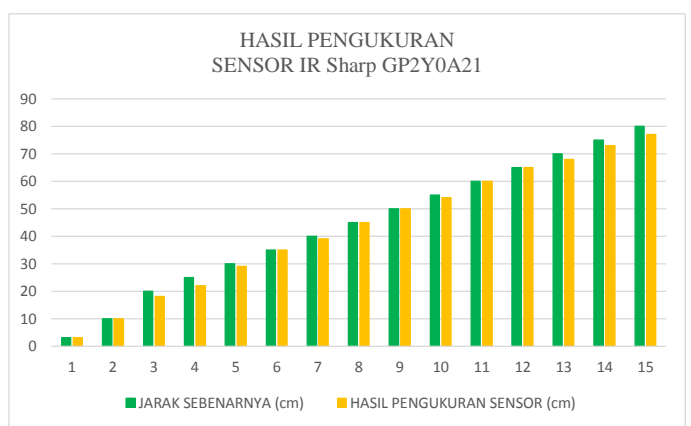

Grafik 2 Pengujian Sensor Ultrasonik Berdasarkan Jenis Bahan

Perancangan tongkat ultrasonik untuk penyandang tuna netra yang menggunakan teknologi sensor ultrasonik PING dan sensor sharp IR GP2Y0A21 merupakan usaha penelitian yang dilakukan untuk membantu kewaspadaan dan mobilitas para penyandang tuna netra.

\section{KESIMPULAN}

Hasil penelitian mengenai perancangan tongkat tuna netra menggunakan sensor ultrasonic dan sensor sharp IR GP2Y0A21 dapat disimpulkan sebagai berikut:

1. Penelitian ini telah menghasilkan rancangan tongkat ultrasonik untuk penyandang tuna netra dengan menggunakan teknologi sensor untuk membantu kewaspadaan dan mobilitas tuna netra yang mampu mendeteksi objek pada jarak antara 0 sampai dengan 100 cm untuk sensor PING depan, kanan dan kiri dengan indikator berupa suara dari buzzer, sementara untuk mendeteksi objek lubang dengan menggunakan sensor sharp IR GP2Y0A21 jarak yang dapat terdeteksi antara 15-80 $\mathrm{cm}$, dengan indikator berupa motor DC yang berputar dan menghasilkan getaran;

2. Tongkat hasil rancangan yang dihasilkan memiliki fitur rangka dengan bahan alluminium, ini dikarenakan alluminium memiliki berat beban yang lebih ringan dibandingkan dengan besi maupun fiberglass sehingga penggunanya lebih nyaman dan lebih efisien. Tongkat ini juga memiliki ukuran yang fleksibel, dapat ditentukan ukuran panjangnya sesuai dengan kebutuhan si penggunannya. Untuk rumah atau kotak tempat peletakan rangkaian sensor dan rangkaian elektronik lainnya, penulis menggunakan akrilik yang bersifat ringan dan transparan, namun tetap kuat dan kokoh untuk menopang hardware berupa rangkaian elektronik dan pendukung lainnya; dan

3. Secara keseluruhan alat sudah dapat digunakan dengan baik. Namun masih ada kekurangan, misalnya sensor pada alat ini masih belum bisa bekerja secara maksimal, salah satu penyebabnya adalah kondisi jalan yang dilalui berubahubah sehingga mempengaruhi besarnya noise yang menyebabkan berkurangnya sebagian fungsi dari kedua sensor tersebut, selain itu bunyi yang dihasilkan buzzer masih sangat terbatas sehingga 
dalam keadaan dengan lingkungan yang menghasilkan suara lebih dominan/keras dari buzzer, maka pengguna akan mengalami kesulitan dalam mendengar dan mengidentifikasi bunyi yang dikeluarkan oleh buzzer tersebut.

\section{DAFTAR PUSTAKA}

Arminda, Gatra Wikan, dan Hendria-wan. 2012. Desain Sensor Jarak dengan Output Suara Sebagai Alat Bantu Jalan Bagi Tuna Netra. Skripsi, Jurusan Teknik Elektro, Politeknik Negeri Surabaya, Surabaya.

Dwiono, Wakhyu, dan Novita Posma, Siska. 2014. Alat Bantu Navigasi Penyandang Tuna Netra Menggunakan Sensor Ping dan Buzzer. Jurnal Teknik Elektro dan Komputer, Politeknik Caltex, Riau.

Nugroho, Anung Budi. 2011, Perancangan Tongkat Tuna Netra Menggunakan
Teknologi Sensor Ultrasonik Untuk Membantu Kewaspadaan dan Mobilitas Tuna Netra. Skripsi, Jurusan Teknik Industri, Fakuktas Teknik, Universitas Sebelas Maret, Surakarta.

Subandi. 2009. Alat Bantu Mobilitas Untuk Tuna Netra Berbasis Elektronik. Jurnal Teknologi, Institut Sains \& Teknologi AKPRIND, Yogyakarta.

Suparman, Akhmad, dan Muslimah Inong Dista. 2012. Sistem Kendali Jarak Jauh Pintu Pagar Otomatis dengan Security System. Skripsi, Fakultas Teknik, program sarjana, Universitas Hasanuddin, Makassar.

Zainuddin Putra, Rakhmat, dan Hatta Mimbar, Ahid. 2014. Perancangan Tongkat Elektronik. Skripsi, Fakultas Teknik, Universitas Hasanuddin, Makassar. 